\title{
A CONSTRUÇÃO DA IDENTIDADE DIDÁTICA DOS LICENCIANDOS EM PEDAGOGIA DE UMA FACULDADE PRIVADA DO INTERIOR BAIANO
}

\author{
Luiz Carlos Marinho de Araujo iD 1
}

\section{Resumo}

Devido a Didática estar vinculada ao fazer docente, muitas reflexões vêm constituindo-se, desde a sua gênese no século XVII, a partir das ideias de Comenius, com a Didática Magna, até os dias atuais acerca da construção da Identidade Didática (ID) do licenciando, propositivo deste estudo. A Didática, nas últimas décadas, tem merecido destaque ao [re]pensar o processo formativo do estudante Pedagogo, seja na formação inicial ou em serviço. Neste estudo de abordagem qualitativa, optou-se pela técnica descritiva ao apresentar e discutir as características que constituem a ID do professor/graduando no curso de Pedagogia de uma Faculdade privada do interior baiano. Almeja-se ampliar as discussões sobre a importância de constituir a ID do licenciando em Pedagogia como dispositivo para o aprimoramento do processo de ensino e aprendizagem, tendo como base a inquietação: quais as concepções de Didática os estudantes de Pedagogia de uma Faculdade privada do interior da Bahia apresentam para constituir sua Identidade Didática? Os dados foram formados com a realização do questionário diagnóstico efetivado na disciplina de "Didática: competências e habilidades docentes", ministrada pelo autor deste artigo. A análise dos dados aconteceu mediante orientação do Método Pragmático, a partir da Tríade metodológica - Construção, [Des]construção e [Re]construção dos dados. Analisou-se os dados, tendo como base as pesquisas de Candau (2012), Geraldo (2014) e Libâneo (2006). A efetivação da pesquisa possibilitou significativas reflexões que contribuíram com a construção da Identidade Didática dos licenciandos em Pedagogia, de forma a superar a visão tecnicista de Didática que os alunos apresentaram.

Palavras-chave: Didática; Licenciatura em Pedagogia; Identidade Didática.

\section{THE CONSTRUCTION OF THE DIDACTIC IDENTITY OF GRADUATES IN PEDAGOGY IN A PRIVATE FACULTY IN THE INTERIOR BAHIA}

\section{Abstract}

Due to Didactics being linked to the teaching practice, many reflections have been constituted, since its genesis in the 17th century, from the ideas of Comenius, with the Didactic Magna, to the present day about the construction of the Didactic Identity (DI) of the Licensing, purpose ofthis study. Didactics, in

${ }^{1}$ Doutorando em Educação em Ciências e Educação Matemática pela Universidade Estadual do Oeste do Paraná, (UNIOESTE). E-mail: marinhoaluiz1@gmail.com 
recent decades, has been highlighted when [re]thinking the educational process of the Pedagogue student, whether in initial training or in service. In this study with a qualitative approach, the descriptive technique was chosen to present and discuss the characteristics that constitute the ID of the teacher/graduate student in the Pedagogy course of a private college in the interior of Bahia. The aim is to broaden the discussions on the importance of constituting the undergraduate student's ID in Pedagogy as a device for the improvement of the teaching and learning process, based on the concern: what are the conceptions of Didactics for Pedagogy students from a private Faculty in the countryside from Bahia present to constitute your Didactic Identity? Data were formed with the completion of the diagnostic questionnaire carried out in the subject "Didactics: teaching skills and abilities", taught by the author of this article. Data analysis took place under the guidance of the Pragmatic Method, from the methodological Triad - Construction, [De]construction and [Re]construction of data. Data were analyzed based on research by Candau (2012), Geraldo (2014) and Libâneo (2006). The realization of the research allowed for significant reflections that contributed to the construction of the Didactic Identity of the undergraduates in Pedagogy, in order to overcome the technical view of Didactics that the students presented.

Keywords: Didactics; Degree in Pedagogy; Didactic identity.

\section{Apontamentos iniciais}

Os termos "ensino" e "aprendizagem" sempre estiveram associados a um mesmo sentido (ensino-aprendizagem), o que tem possibilitado algumas discussões sobre a necessidade de desvinculá-los, pois ambos apresentam conceitos e características distintas, mesmo interligados com as relações entre professor e aluno. Desse modo, havendo na Didática o papel de promover essa relação, pois "tratar do processo didático focalizando as formas e as práticas de interação entre professores e alunos como uma das dimensões da didática implica resgatar o percurso da área situando-a nos diferentes momentos históricos" (MARTINS, 2012, p. 14).

Alguns dos momentos que marcaram o percurso da Didática estão na centralidade da hierarquia de poder. Nele, o professor ensina e o aluno aprende; o docente é visto como técnico para executar as 'receitas metodológicas' adquiridas nas formações personificadas pelo "racionalismo técnico" (DINIZPEREIRA, 2014, p. 35). Além de serem reproduzidas em suas aulas expositivas como objetivos conceituais para que os estudantes exerçam a seu papel, não ultrapassando a função de memorizar para reproduzir.

Tais debates emergem com as reflexões sobre "o que ensinar" e o "como ensinar", ou seja, o professor é quem determina "o que" e "como" ensinar. Essas atitudes podem ter contribuído para que, ao longo da história, os alunos ocupassem o lugar de meros espectadores de sua própria aprendizagem. Consequentemente, deixando à margem "o como aprender", estando vinculado 
ao estudante e às suas diferentes formas de aquisição da aprendizagem atreladas às suas necessidades.

As acepções em relação a discussão do "o que" e "o como" ensinar têm dado à Didática o papel de destaque no processo de ensino e aprendizagem, porém ainda afeiçoado ao ato de ensinar, pouco discutido sobre a ação de aprender. Essas relações são pertinentes ao conceito de Didática como "arte e técnica" de ensinar. O "termo didática é derivado do grego didaktiké, que significa, em outras palavras, "arte de ensinar". Atualmente, diversas são as definições de Didática, mas quase a totalidade delas refere-se como técnica, ciência ou arte de ensinar" (PEREIRA; FRANCISCATTO, et al, 2019, p. 12).

Pretende-se analisar ao final das reflexões amparadas pelo problema de pesquisa: quais as concepções de Didática os estudantes de Pedagogia de uma Faculdade privada do interior da Bahia apresentam para constituir sua Identidade Didática, e proporcionar discussões acerca das características que constituem a Identidade Didática (ID) do estudante de Pedagogia como subsídio para aquisição de habilidades necessárias ao ato de ensinar.

O termo Identidade Didática, inaugurado neste trabalho, tem como adjetivo o perfil profissional que o professor adquire ao longo do seu fazer docente através de sua "práxis pedagógica" (CALDEIRA; ZAIDAN, 2013), constituindo parte integrante do conjunto de atributos pedagógicos e humanos consolidados na Identidade docente (GOMES, 2016; OLIVEIRA, et al, 2006; IZA, et al, 2014). Ademais, tendo a aprendizagem centrada nas necessidades dos estudantes como referência para o desenvolvimento do ensino e aprendizagem.

\section{Método para constituição e análise dos dados}

Os dados para pesquisa foram constituídos e apoiados no Método Pragmático $^{1}(\mathrm{MP})$, concedendo ao pesquisador maior autonomia em suas pesquisas, possibilitando-o criar suas próprias ferramentas metodológicas ou aglutinar estratégias de outros métodos já consolidados em pesquisa cientificas para constituir e analisar os dados. O Método Pragmático está composto por três etapas, compondo a Tríade metodológica CDR - Construção, [Des]construção e [Re]construção dos dados.

${ }^{1}$ Método constituído pelo autor deste artigo. 


\section{Diagrama 1 - Etapas do Método Pragmático}

\section{Construção}

\section{[Re]construção | [Des]construção}

Fonte: estruturado pelo autor.

Em uma pesquisa científica, a fase de organização metodológica é uma área de bastante discussão e indecisão por parte do pesquisador. Havendo sobre ela grande produção acadêmica, o que acaba contribuindo com algumas inquietações sobre 0 delineamento metodológico da investigação. Principalmente na pesquisa de abordagem qualitativa, esses questionamentos não são difíceis de serem identificados. Como sublinha Lüdke e André (2020, p. 12), "[...] ainda parecem existir muitas dúvidas sobre o que realmente caracteriza uma pesquisa qualitativa $[\ldots]$ ".

$\mathrm{Na}$ literatura discerne-se as diferentes interpretações sobre os termos: abordagem, técnica, instrumento e método, termos que compõem as fases da pesquisa científica. De modo a corroborar com a diferenciação entre as fases da pesquisa, o Método Pragmático está estruturado de acordo com o Diagrama 2, referendado em alguns autores como: Lüdke e André (2020), Minayo (2005), Gil (2002), Flick (2009) e Marconi e Lakatos (1999).

\section{Diagrama 2 - Fase para constituição dos dados}



Fonte: montado pelo autor.

Na etapa de Construção dos dados enquanto base, conforme explicitado no Diagrama 1, proposto pelo Método Pragmático, o estudo teve como abordagem a pesquisa qualitativa. O estudo qualitativo, além de oportunizar a 
reflexão sobre determinado fenômeno, "preocupa-se com a compreensão interpretativa da ação social" (MINAYO; et al, 2005, p. 81). "Dessa forma, a abordagem qualitativa atua levando em conta a compreensão, a inteligência dos fenômenos sociais e o significado e a intencionalidade que atribuem os atores" (MINAYO, 2005, p. 82).

As autoras Lüdke e André (2020, p. 14), referendadas em Bogdan e Biklen (1982), destacam que "[...] a pesquisa qualitativa supõe o contato direto e prolongado do pesquisador com o ambiente e a situação que está sendo investigada, via de regra, pelo trabalho intensivo de campo". Partindo das concepções dos autores acerca da pesquisa qualitativa, este estudo foi desenvolvido a partir da disciplina "Didática: competências e habilidades docentes", lecionada pelo autor deste artigo em uma turma de licenciandos em Pedagogia de uma Faculdade privada do interior da Bahia.

Para tanto, foi anteposta a técnica descritiva porque o desígnio da pesquisa estava concentrado na perspectiva de apresentar e discutir as características que constituem a Identidade Didática (ID) a partir das concepções dos licenciandos em Pedagogia. Logo, de forma a ampliar as discussões sobre a importância da Didática no processo formativo do professor (futuro professor) como mecanismo de obtenção das habilidades necessárias para o fazer docente. Segundo Gil (2002, p. 42), "as pesquisas descritivas têm como objetivo primordial a descrição das características de determinada população ou fenômeno ou, então, o estabelecimento de relações entre variáveis". Para Triviños (1987, p. 110), "a maioria dos estudos que se realizam no campo da educação é de natureza descritiva. O foco essencial destes estudos reside no desejo de conhecer a comunidade, seus traços característicos [...]".

Atrelado à técnica descritiva, adotou-se, como instrumento de construção dos dados, algumas questões realizadas no primeiro contato com a turma; o questionário diagnóstico foi usado como estratégia pelo professor da disciplina para conhecer as necessidades da turma. Gil (2002, 42) pontua que outra característica para a pesquisa descritiva "está na utilização [...] de questionário" para constituição dos dados. O autor ainda ressalta que:

A elaboração de um questionário consiste basicamente em traduzir os objetivos específicos da pesquisa em itens bem redigidos. Naturalmente, não existem normas rígidas a respeito da elaboração do questionário. Todavia, é possível, com base na experiência dos pesquisadores, definir algumas regras práticas a esse respeito (GIL, 2002, p. 116).

Em uma das regras pontuadas pelo autor, referindo-se à elaboração do questionário, ele destaca que em um questionário "devem ser incluídas apenas as perguntas relacionadas ao problema proposto" (GIL, 2002, 116). Com a definição das fases apresentadas no Diagrama 2, para constituição dos dados, finalizou-se a primeira etapa proposta pelo Método Pragmático, sendo a etapa para Construção dos dados. 
Encaminhando-se o desenho metodológico, realizou-se a segunda etapa: [Des]construção dos dados. A efetivação dessa etapa deu-se a partir das quinze questões, com base no Quadro 2, disponibilizadas para os estudantes na realização do diagnóstico inicial. Foram selecionadas apenas quatro questões para compor o "corpus" (BARDIN, 2016) desta pesquisa. As referidas questões foram fragmentadas, codificadas e categorizadas, tendo o quadro analítico (modelo), Quadro 1, como recurso para desconstrução dos dados. Segundo Bardin (2016), "a categorização é uma operação de classificação de elementos constitutivos de um conjunto por diferenciação e, em seguida, por reagrupamento segundo o gênero (analogia) com os critérios previamente definidos" (BARDIN, 2016, p. 147).

O quadro analítico, adotado como recurso metodológico para desmontar os dados, possibilitou identificar as ideias dos estudantes sobre Didática e suas relações com o processo de ensino e aprendizagem. As informações contidas no quadro foram desmontadas a partir dos dados individuais que o formulário Google Forms disponibiliza. O quadro analítico será usado na etapa de discussão dos dados como suporte para a [Re]construção e reflexão dos dados.

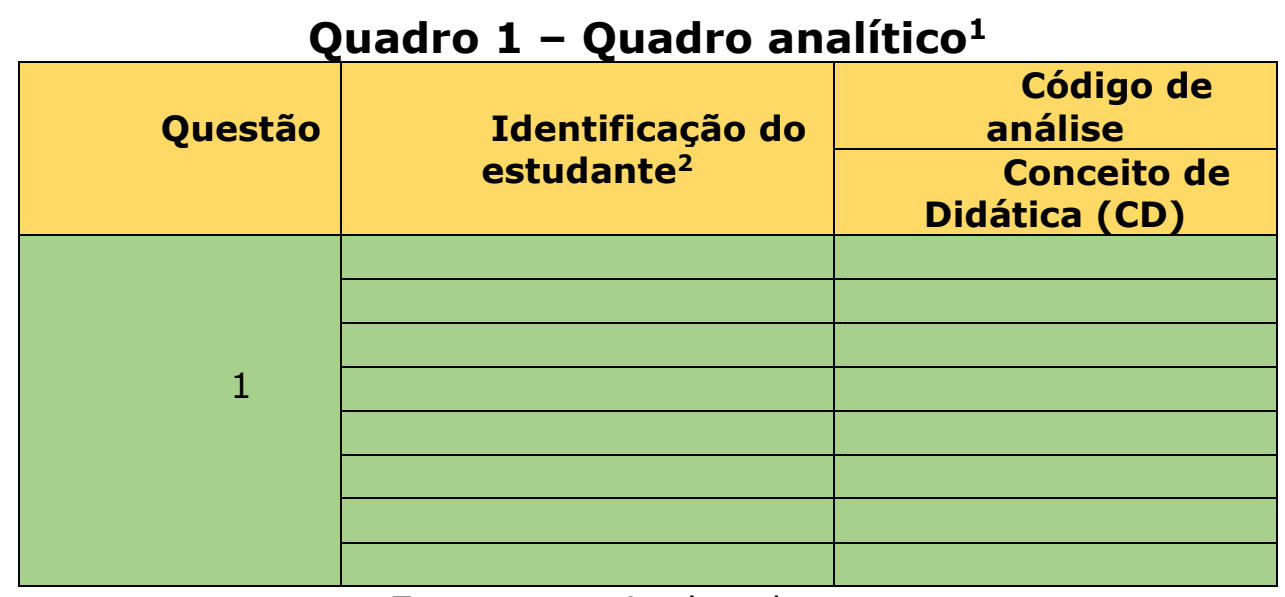

Fonte: organizado pelo autor.

Com os dados desmontados, dispondo do Quadro 1 como recurso, foi possível realizar a etapa final proposta pelo Método Pragmático na etapa de [Re]construção dos "corpus". Nessa etapa, os dados foram analisados separadamente e reconstruídos, estando apoiados nas referências contidas no Quadro 1. O código de análise Conceito de Didática (CD) originou a categoria de análise. A categoria foi considerada emergente, pois os dados construíram-se após o "processo analítico", perfil do "método indutivo [que] implica produzir as categorias a partir das unidades de análise construídas a partir do "corpus" (MORAES; GALIAZZI, 2007, p. 22-23).

\footnotetext{
${ }^{1}$ Modelo do quadro usado para a desmontagem dos dados, apenas da primeira questão.

2 Para manter o anonimato, na análise dos dados, usou-se a letra inicial do nome do estudante. 
No decurso de [Re]construção dos dados, última etapa do Método Pragmático, foi possível constituir uma linguagem ilustrativa com quadros e gráficos, visando a melhor compreensão das reflexões propostas pela pesquisa. Assim sendo, de forma a realizar uma discussão amparada nos resultados referendados nos autores que discutem a problemática da Didática e as relações entre ensino e aprendizagem. As ponderações foram embasadas pelo referencial básico, sustentadas pelos autores Geraldo (2014), Candau (2012), Martins (2012) e Libâneo (2006).

Todas as discussões metodológicas fomentadas nesta seção compõem o Método Pragmático para análise dos dados, constituindo-se como um propositivo metodológico para as futuras pesquisas científicas que adotem o MP para a constituição e reflexão dos seus dados. O método apresentado nesta seção não tem relação com o termo Didática porque neste artigo o conceito de Didática é discutido como abordagem didática, e não apenas como técnica para ensinar.

As ideias ponderadas acerca da Didática versam como procedimento no qual se envolvem atitude, método, valores e ações que corroboram com todo o processo de ensino e aprendizagem que, nos dias atuais, não acontece apenas na aquisição de uma aprendizagem conceitual. As reflexões posteriores estarão apresentadas nesta perspectiva: a Didática a partir de uma visão globalizada de todas as variáveis que compõem o ensino e a aprendizagem.

\section{Altercação a partir dos dados}

Inconscientemente, as discussões entorno do conceito de Didática são afeiçoadas ao técnico, ao procedimento, à metodologia, ao método, à estratégia etc., ou seja, mesmo na contemporaneidade, o termo Didática ainda está ligado a concepções do século XVII, como "arte e técnica de ensinar" (PEREIRA; FRANCISCATTO, et al, 2019, p. 12, grifo nosso). Mesmo na modernidade, muitas pesquisas apresentam argumentos entorno da Didática enquanto técnica, é preciso que essa visão simplista seja transposta para uma visão holística para além do técnico.

Os dados para pesquisa foram constituídos durante as aulas da disciplina "Didática: competências e habilidades docentes", realizada pelo autor deste artigo em uma Faculdade privada do interior da Bahia, ministrada para uma turma de Pedagogia do terceiro/quarto semestre. A disciplina compõe a parte obrigatória do currículo do curso de Pedagogia da referida instituição. Para o uso dos dados do questionário diagnóstico realizado no primeiro contato com a turma, foi solicitada à coordenação da Faculdade a autorização para que as discussões ocorridas durante as aulas pudessem compor este e outros estudos relacionados com a disciplina em questão.

O questionamento: "quais as concepções de Didática os estudantes de Pedagogia de um Instituto de Ensino Superior (IES) do interior da Bahia apresentam para constituir sua Identidade Didática", que embasa toda a pesquisa, emergiu durante as aulas realizadas em formato remoto pela plataforma digital Google Meet, em virtude da pandemia do novo Coronavírus. 
Dessa forma, o questionário diagnóstico foi disponibilizado na primeira aula como estratégia para que os estudantes relatassem suas concepções antes mesmo das discussões da disciplina. O questionário foi desenvolvido pela ferramenta Google Forms e divulgado para a turma pelo sistema Cerbrum, adotado pela instituição.

O referido questionário estava composto por duas seções: a primeira, Informações sobre a disciplina, abarcava perguntas pontuais sobre a ementa; a segunda seção, Informações pessoais, apresentava o perfil da turma. No questionário havia quinze questões, Quadro 2, relacionadas ao planejamento da disciplina, porém, para essa pesquisa, subtraiu-se quatro indagações contidas na primeira seção. As questões tratadas neste artigo estão sinalizadas no Quadro 2 , as demais serão analisadas em estudos posteriores com reflexões acerca do curso de Pedagogia.

\section{Quadro 2 - Estrutura do questionário diagnóstico}

\section{QUESTÕES NO QUESTIONÁRIO DIAGNÓSTICO}

\section{Seção I: Informações sobre a disciplina}

1. Defina Didática com uma palavra.

2. No decorrer do curso de Pedagogia você já estudou alguma disciplina relacionada à Didática?

3. Você acredita que a Didática influencia na prática pedagógica do(a) professor(a)?

4. Você acredita na possibilidade da existência de uma Didática Ideal?

5. Dos tipos de Didática. Qual(is) você tem conhecimento?

6. Você já realizou algum planejamento escolar?

7. Dos itens relacionados ao planejamento escolar. Qual(is) você tem mais dificuldade?

8. Qual seu conhecimento sobre a Base Nacional Comum Curricular - BNCC?

9. Você se considera um(a) profissional competente?

10. Quais habilidades você acredita que precisa desenvolver para se tornar um(a) professor(a) competente?

11. Quais suas expectativas sobre a disciplina?

12. Seu nome completo.

Seção II: Informações pessoais

13. Além dessa graduação você tem outra?

14. Você tem experiência com a docência?

15. Por que você decidiu cursar Pedagogia?

Fonte: organizado pelo autor.

A turma era composta por dez estudantes das regiões próximas à sede da Faculdade, sendo acadêmicos que não atuam na docência, mas trabalham em outras áreas. Dos dez alunos matriculados na turma, oito responderam ao questionário. Porém, na etapa de [Des]construção dos dados, no preenchimento do quadro analítico, identificou-se duas respostas duplicadas, sinalizadas no Quadro 3, as mesmas foram eliminadas, totalizando a participação de seis estudantes. 


\begin{tabular}{|c|c|c|}
\hline Questão & $\begin{array}{l}\text { Identificação do } \\
\text { estudante }^{1}\end{array}$ & $\begin{array}{c}\begin{array}{c}\text { Código de } \\
\text { análise }\end{array} \\
\text { Conceito de } \\
\text { Didática (CD) } \\
\end{array}$ \\
\hline \multirow{8}{*}{1} & S1 & Planejamento \\
\hline & $\mathrm{A} 1$ & Orientar \\
\hline & $\mathrm{A} 2$ & Orientar \\
\hline & $\mathrm{H} 1$ & Método \\
\hline & $\mathrm{H} 2$ & Método \\
\hline & $E$ & Conhecimento \\
\hline & $\mathrm{S} 2$ & Informação \\
\hline & J & Estudo \\
\hline
\end{tabular}

Fonte: organizado pelo autor.

Em virtude de os estudantes não terem experiência com a docência, foi preciso organizar um planejamento escolar em uma das aulas, oportunizando que a turma tivesse contato com práticas direcionadas ao ato de ensinar. "O planejamento é um processo de racionalização, organização e coordenação da ação docente, articulando a atividade escolar e a problemática do contexto social" (LIBÂNEO, 2006, p. 222). Restabelecendo as discussões acerca do problema de pesquisa, apresentaremos as interpretações das quatro questões acarretadas para o debate e organizadas na categoria de análise.

\subsection{Categoria - Conceito de Didática}

A primeira pergunta visava identificar nos estudantes a definição de Didática, para isso eles deveriam escrever apenas uma palavra que submetesse a concepção de Didática. Para os licenciandos, a Didática representa: método, orientar, informação, planejamento, conhecimentos e estudo. Observando os conceitos, é possível perceber que mesmo a turma não tendo atuado na área da educação, a compreensão de Didática é sempre a mesma, eternizada a procedimentos metodológicos sobre o "que fazer" em sala de aula (CANDAU, 2012, p. 13).

Pimenta (1999), ao discutir os "saberes pedagógicos", destaca que "os alunos da licenciatura, quando arguidos sobre o conceito de didática, dizem em uníssono, com base em suas experiências, que "ter didática é saber ensinar" e "que muitos professores sabem a matéria, mas não sabem ensinar". Portanto, didática é saber ensinar" (PIMENTA, 1999, p. 24).

Pensar a Didática a partir das concepções expostas pelos estudantes é protocolar o tecnicismo como mola propulsora da Didática, mesmo nos dias atuais, onde o ensino vem exigindo outras habilidades tanto do professor quanto do estudante. É urgente a necessidade de transcender a concepção de Didática do século XVII, considerando apenas os âmbitos técnicos, o fazer, o prático, o método. Pensar a Didática para a contemporaneidade é acreditar que o

${ }^{1}$ Para manter o anonimato, na análise dos dados, usou-se a letra inicial do nome do estudante. 
procedimento metodológico é o caminho para alcançar o objetivo do ensino, sendo a aprendizagem.

As ideias colocadas pelos estudantes não estão erradas dentro do contexto da definição de "Didática Instrumental", pontuada por Candau (2012, p. 23). "[...] A Didática como necessariamente vinculada a uma visão tecnicista da educação", centrada no ensino/professor como "[...] um bom executador de tarefas [...]" (MARTINS, 2012, p. 16), e o aluno/aprendiz como subordinado. No presente, diversos autores ainda realçam a Didática atrelada ao contexto da Didática Magna (1621-1657).

Ao discutir-se um conceito, é necessário entender o contexto no qual ele foi apresentado. O termo Didática emergiu no século XVII pelas ideias de Comenius, enraizado por uma circunstância específica da época. "As ideias parecem quase sempre nascer na instantaneidade do momento em que são expressas. Parecem não ter passado" (ASTOLFI; DEVELAY, 1990, p. 7). "[...] O ensino da Didática assume certamente uma perspectiva idealista e centrada na dimensão técnica do processo de ensino-aprendizagem" (CANDAU, 2012, p. 18), que não é a mesma conjuntura do século XXI. Ou seja, é preciso entender o cenário histórico, social, político, científico etc. da época em que o termo foi mencionado, no qual o processo de ensino e aprendizagem apresentava outras perspectivas e já não contempla mais as demandas e necessidades sociais na atualidade.

Ao serem questionados se durante o curso de Pedagogia tiveram alguma disciplina relacionada à Didática, 37,5\% dos licenciandos colocaram sim, 25\% não, e 37,5\% pontuaram não lembrar. Essa questão torna-se relevante porque a Didática faz (ou deveria fazer) parte do processo formativo dos licenciandos. Sobretudo por o curso de Pedagogia ser uma licenciatura centrada no ensino e na aprendizagem.

Todo processo de formação de educadores - especialistas e professores - inclui necessariamente componentes curriculares orientados para o tratamento do "que fazer" educativo, da prática pedagógica. Entre estes, a didática ocupa um lugar de destaque (CANDAU, 2012, p. 13).

Consagradamente, identificamos na bibliografia alguns tipos de Didática. Para essa discussão destacamos apenas as duas apresentadas por Candau (2012, 22-23) - "Didática Instrumental" e a "Didática Fundamental". Como estratégia para saber dos estudantes sobre a(s) qual(is) eles tinham conhecimento, foi feita a seguinte questão: dos tipos de Didática listados abaixo, qual(is) você tem conhecimento?

O Gráfico 1 torna evidente que a maioria dos discentes desconhecem os tipos de Didática, resguardado pelo fato deles não terem experiência na docência e ainda não terem estudado uma disciplina que discutisse as questões da Didática, como ficou explicitado na questão 2, Quadro 2. 


\section{Gráfico 1 - Tipos de Didática}



Fonte: reorganizado a partir dos dados apresentados pelo Google Forms.

Araújo (2020) destaca que as formações dos professores sempre estiveram vinculadas às práticas tecnicistas, pensando o professor como um profissional técnico. Tendo o docente frequentado uma formação técnica, automaticamente ele se constituirá pedagogicamente por uma "Didática Instrumental" (CANDAU, 2012, p. 22-23). Para as autoras André e Cruz (2012), a "Didática Instrumental" está "centrada na aplicação de métodos e técnicas para atingir o conhecimento científico, em busca da qualidade dos produtos, da eficiência e da eficácia, propõe-se uma Didática atenta à necessidade de favorecer a formação de educadores críticos e conscientes do papel da educação na sociedade (ANDRÉ; CRUZ, 2012, p. 445).

Contrapondo a "Didática Instrumental", Candau (2012, p. 23) apresenta a "Didática Fundamental" como a necessidade de colocar a dimensão "técnica, humana e política, no centro configurador de sua temática". É inexistente a ideia de superação de uma Didática, de forma a caracterizar a "Instrumental" inferior ou desnecessária à "Fundamental". Ambas se complementam em virtude de as três dimensões estarem interligadas. A "[...] prática pedagógica, exatamente por ser política, exige a competência técnica. As dimensões políticas, técnicas e humana da prática pedagógica se exigem reciprocamente" (CANDAU, 2012, p. 23).

A prática pedagógica é, sem dúvida, "espelho" da concepção de ensino e aprendizagem do professor, que contribui para a construção da "Identidade docente", uma identidade também constituída pelo seu processo formativo. "Assim, discussões sobre programas de formação docente devem investigar como a relação do professor com o seu próprio processo de aprender é trabalhada, e de que maneira ocorre a construção de sua identidade docente" (OLIVEIRA, et al, 2006, p. 548). Portanto, os docentes refletem em seu fazer pedagógico suas percepções sobre o processo de ensino e aprendizagem. Quando questionado aos alunos sobre a possível influência da Didática na prática docente, a maioria dos estudantes, sendo $62,5 \%$, representou acreditar na influência da Didática na prática pedagógica do professor/pedagogo, como é visível no Gráfico 2. 


\section{Gráfico 2 - Influência da Didática na atuação do professor}

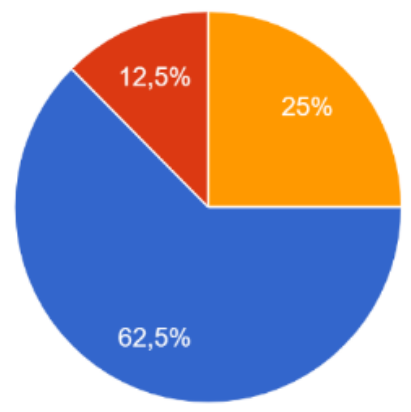

Influencia

Não influencia

Influencia pouco

Fonte: Google forms.

Tradicionalmente, a Didática sempre esteve atrelada ao "saber fazer". Raramente se relaciona a ação didática com a relação entre aluno e professor. Isso se confirma ao observar o uso do termo ensino-aprendizagem, e não ensino e a aprendizagem, logo, centralizando o professor como protagonista do ato de ensinar. A autora Martins (2012) sublinha que "tais enunciados revelam a importância da didática na formação do professor, focalizando as formas e as práticas de interação entre professores e alunos na busca do conhecimento" (MARTINS, 2012, p. 11). Freire (1996) destaca que, ao ensinar, também se aprende. Dessa forma, é preciso pensar a Didática não apenas como o fazer pedagógico do professor, mas sendo uma relação entre ambos os personagens da história do ensino e da aprendizagem.

Essa realidade é confirmada ao observar as práticas pedagógicas por vezes centradas em aulas explicativas e expositivas, tendo como base a transmissão de conteúdos pelo professor que, para muitos, ainda é o possuidor do conhecimento em sala de aula. Desse modo, restando aos estudantes a única função de memorizar e reproduzir as explicações do professor. Didaticamente, o ensino sempre esteve muito mais atrelado ao ato de ensinar do que o de aprender com aulas expositivas e pouca (ou nenhuma) interação entre professor e aluno.

As reflexões propostas nesta seção têm significativa importância para a construção da Identidade Didática do estudante de licenciatura acoplada a identidade docente, afinal, "a identidade [de um professor] não é um dado imutável e tampouco externo, que possa ser adquirido. Mas é um processo de construção do sujeito historicamente situado" (PIMENTA, 1999, p. 18), assim como Pimenta (1999), Iza et al (2014, p. 274) sublinha "[...] que a identidade docente é dinâmica e tem relação direta com o contexto social no qual se está inserido". Dessa maneira, a Identidade Didática do profissional da docência é gradativamente construída ao longo de suas experiências, formação, no exercício da prática, nas relações com os pares.

A ID não se consolida ao término da licenciatura, ela é edificada na práxis do fazer pedagógico, construído pelas relações entre o "saber" e o "saber fazer" (CARVALHO; GIL-PÉREZ, 2011, p. 16). A Identidade Didática é concebida pela 
triplicidade da ação-reflexão-ação, que Freire (1996) já sinalizava como um dos saberes necessários para o ato de educar.

\section{Discussão teórica}

"[...] Aquele professor não tem didática..."; "Ele tem conhecimento, mas não sabe comunicar..."; "O professor conhece o assunto da sua disciplina, mas não sabe transmitir..." (MARTINS, 2012, p. 11).

As afirmações acima estão presentes nas falas de muitos estudantes nos corredores das instituições de ensino, seja da Educação Básica ou de nível superior. Os alunos usam desses discursos para caracterizar um professor que não apresenta o domínio do conteúdo ou não possui metodologia. Dessa forma, eles acabam categorizando os "bons" e os "maus" professores. Historicamente, o "bom" professor é aquele que cumpre, na íntegra, os conteúdos curriculares ao final da unidade, independente dos alunos aprenderem. Os relatos ilustrados acima estão diretamente ligados ao fato de o professor ter ou não a Didática em suas aulas, ou seja, para os estudantes: o bom professor é aquele que domina o "saber" e também o "saber fazer" (CARVALHO; GIL-PÉREZ, 2011, p. 16).

A Didática e, automaticamente, o professor estão centrados na exposição, e sempre ligados ao Ensino Tradicional, "[...] o papel do professor se caracteriza pela garantia de que o conhecimento seja conseguido e isto independentemente do interesse doe vontade do aluno [...]" (MIZUKAMI, 1986, p. 8), e uma das formas de superar a "didática tradicional" (CANDAU, 2012, p. 16) foi a implementação do Ensino por Redescoberta, tornando-se uma das maneiras de aproximar o estudante das atividades científicas por meio do método científico.

O ensino tradicional mostrou-se ineficiente quando se começou a dar prioridade ao ensino do "método científico", e assim surgiu uma nova maneira de ensinar Ciências, o ensino por redescoberta. $\mathrm{Na}$ prática, este se revelou equivocado, mas teve o mérito de romper com a tradição do ensino de Ciências para a transmissão-recepção" (CAMPOS; NIGRO, 1999, p. 26, grifo do autor).

Dessa forma, teríamos uma Didática mais interativa e participativa. O Ensino por "Redescoberta" é visto como válvula de escape para promover a interação entre os estudantes e os professores por meio do método científico, mesmo que no modelo de roteiro para o aluno apenas executar. É pertinente ressaltar que muitas dessas práticas de exposição e memorização estavam/estão relacionadas à formação técnica acessada pelo professor. "Os modelos mais difundidos de formação de professores são aqueles relacionados ao modelo da racionalidade técnica" (DINIZ-PEREIRA, 2014, p. 35).

No decurso de ensino e aprendizagem, as três dimensões - técnica, humana e política - explicitada por Candau (2012) se complementam. A educação acontece exatamente na interação do sujeito com suas relações, não apenas na aquisição das habilidades especificas adquiridas na escola por meio 
do ensino. "A educabilidade humana [...] originou-se e desenvolveu-se ao longo do processo histórico-social humano, através do qual o homem produz a sua existência" (GERALDO, 2014, p. 19). Com o avançar dessas produções, para suprir as suas necessidades humanas, o homem passa a produzir conhecimento e vem ao longo dos séculos buscando o aprimoramento de suas produções, perpassando por gerações que buscam compreender o termo conhecimento como resposta a uma verdade.

"É importante notar, no entanto, que ter uma crença verdadeira não equivale necessariamente a ter conhecimento" (O'BRIEN, 2013, p. 34). As discussões acerca da Teoria do conhecimento não se esgotam com este estudo, a intenção é destacar que no processo de evolução humana, "a educação em sentido geral [...] destina-se a promover as novas gerações da experiência histórica da humanidade, em seu sentido intelectual, emocional, atitudinal, comportamental, valorativo, moral, ético etc." (GERALDO, 2014, p. 29).

O processo de ensino e aprendizagem relacionado à educação, em um sentido mais restrito, especificamente direcionado ao ambiente escolar,

[...] tem como principal função os processos de ensino e aprendizagem dessa experiência, no que diz respeito prioritariamente ao saber científico, filosófico, artísticos e tecnológico, em condições específicas e adequadas, e aqui surge o fenômeno didático, que deriva do pedagógico, como função de sistematização e organização do processo de ensino-aprendizagem escolar (GERALDO, 2014, p. 29).

As reflexões sobre a Didática giram "no sentido de ser o conjunto das atividades específicas do professor" (GERALDO, 2014, p. 29), que sistematiza e organiza o ensino escolar tendo como objeto de estudo o processo de aquisição da aprendizagem (GERALDO, 2014, p. 29-30). Encontramos na literatura a Didática geral e a Didática específica, ambas voltadas para o encadeamento do ensino e da aprendizagem. Tradicionalmente, "[...] a didática tem sido vista como um conhecimento relacionado a processos de ensino e aprendizagem que ocorrem em ambientes organizados de relação e comunicação intencional, visando a formação dos alunos" (SUANNO; RAJADELL, 2012, p. 9).

Da Didática Magna de Comenius, de 1649, perpassando do século XVII ao século XXI, várias foram as transformações que o processo didático sofreu. Uma dessas mudanças foi a desvinculação da Didática geral da Didática específica. Nesse sentido, superando a ideia de que é possível "ensinar tudo a todos" (SANTOS; SOUZA, 2018 p. 227), característica da Didática pregada por Comenius no século XVII. Desse modo, os estudos na área têm contribuindo para que a Didática seja pensada não apenas como amplitude do ensino e aprendizagem no geral, entretanto como um ensino específico que contribua com um aprendizado próprio de uma área do conhecimento científico.

Em função das subdivisões e das especificidades das áreas do conhecimento científico, a didática se subdividiu em: didática geral e didáticas específicas, também chamadas metodologias 
específicas das matérias de ensino, que por sua vez se subdividem em: didática da história, didática da geografia, didática da Matemática, didática de ciências naturais e outras, que correspondem às didáticas do ensino das diferentes disciplinas em que está dividido o currículo escolar (GERALDO, 2014, p. 31).

Devido a organização curricular dos cursos de licenciatura que ainda apresentam resquício do Ensino Tecnicista, considerando o professor apenas como reprodutor da proposta curricular (TARDIF, 2014), tem-se por consequência dessa realidade, conforme identificamos, a Didática alicerçada apenas por fundamentos teóricos. Assim sendo, inexiste a possibilidade de oferecer ao professor uma 'Autonomia Formativa' que exigiria a formação científica do docente para a atuar a partir das necessidades carecidas pela educação contemporânea.

Os autores Mellado e Carracedo (1993, p. 331) ressaltam que "actualmente, la didáctica de las ciencias cuenta con un cuerpo teórico de conocimiento, se está configurando cada vez más como una disciplinas específicas y desde hace unos pocos años se están estudiando y debatiendo los fundamentos epistemológicos de la misma". É controverso exigir que o professor desenvolva suas aulas tendo uma Didática fundamentada na filosofia e na história da ciência, sem que o docente tenha participado durante seu processo formativo de discussões que abarcassem essas abordagens, de forma a refletir as suas próprias concepções epistemológicas acerca da Natureza da Ciência.

[...] el tema tiene grandes implicaciones didácticas para la formación de profesores de ciencias: si las concepciones epistemológicas de los profesores tienen influencia en su actuación en el aula y las concepciones de los profesores son a menudo implícitas y alternativas, también habrá que aplicar en la formación del profesorado estrategias de cambio conceptual y metodológico (MELLADO; CARRACEDO, 1993, p. 337).

Acredita-se que em uma das mudanças apontadas pelos autores para a formação docente esteja a inserção dos "saberes" (TARDIF, 2014), (PIMENTA, 1999) e (FREIRE, 1996) do professor alinhado a uma formação científica nas propostas curriculares, disponibilizando ao docente assumir uma postura mais atuante na construção e desenvolvimento do seu processo formativo. Dessarte, de forma a propiciar ao educador a aquisição de habilidades científicas para o mesmo constituir sua 'autonomia formativa'. "[...] Um professor é, antes de tudo, alguém que sabe alguma coisa e cuja função consiste em transmitir esse saber a outros" (TARDIF, 2014, p. 31).

É estranho que os professores tenham a missão de formar pessoas e que se reconheça que possuem competência para tal, mas que, ao mesmo tempo, não se reconheça que possuem a competência para atuar em sua própria formação e para controla-la, pelo menos em parte, isto é, ter o poder e o direito de determinar, com outros atores da educação, seus conteúdos e formas (TARDIF, 2014, p. 240). 
É certo afirmar que a formação frequentada pelo professor será instantaneamente executada em sala de aula através de sua Didática, não apenas nos procedimentos metodológicos, mas também na compreensão tida pelo educador acerca de determinadas temáticas diretamente envolvidas com o processo educacional, constituindo, assim, a sua Identidade Didática.

A identidade do professor é, sem dúvida, umas das demandas para o atual contexto educacional, em virtude da elevação das responsabilidades que o docente tem agregado ao fazer pedagógico. A Identidade didática trazida para o cenário desta discussão vincula-se à construção da Identidade docente.

A identidade é entendida aqui como um processo de construção social de um sujeito historicamente situado. Em se tratando da identidade profissional, esta se constrói com base na significação social da profissão, de suas tradições e também no fluxo histórico de suas contradições (IZA, et al, 2014, p. 275).

Assim, sendo a identidade do profissional do magistério delineada pelas suas relações ao longo do seu percurso docente, é válido destacar que a propriedade do professor em sua práxis corrobora para a construção da Identidade Didática, essa coopera para a efetivação da Identidade docente.

\section{Apontamentos finais}

As reflexões oportunizadas neste estudo teórico são discussões pertinentes ao repensar o fazer docente, uma profissão que carece diariamente de adequações e adaptações para atender as demandas que os estudantes e, muitas vezes, o próprio professor necessita para ressignificar sua prática pedagógica em virtude do processo transformacional natural do ser humano. $E$ uma das ações do ato de ensinar que precisa constantemente modificar-se é a Didática, não apenas enquanto metodologia, mas como transformações didáticas que contribuam com o processo de ensino e aprendizagem de alunos mais participativos e atuantes nas mais variadas esferas sociais.

O estudo possibilitou ampliar as discussões sobre a importância da Didática para o processo de ensino e aprendizagem, tendo a Identidade Didática como um dos passos para que o professor constitua sua Identidade docente que não é edificada apenas pelo "como fazer", bastante alinhada a prática pedagógica. A identidade docente é concebida pela amplitude das relações existentes no processo de ensino e aprendizagem através da reflexão diária da práxis pedagógica. Com isso, na mesma proporção com a qual se almeja a formação dos seus estudantes para atuarem ativamente na sociedade contemporânea, assumindo a postura de professor/cidadão crítico e empoderado para enfrentar as reivindicações sociais.

Resumidamente, os debates aqui apontados servirão como base para repensar a atual Didática desenvolvida nas escolas no âmbito nacional, que ainda apresentam características da Didática Magna do século XVII, com perfil de transmissão - memorização - reprodução. Se o objetivo da educação é 
formar estuantes mais participativos, questionadores, ativos etc., é preciso reconsiderar o processo formativo do professor. Afinal, ficou evidente, a partir dessas reflexões, que a formação frequentada pelo educador é a mesma desenvolvida em sala de aula em suas práticas pedagógicas.

Diante do exposto, espera-se que as discussões a respeito da Identidade Didática do pedagogo ganhem lugar de destaque em futuras pesquisas, abordando o quanto é necessário o docente se constituir enquanto um profissional reflexivo, atuante, autônomo a partir da reflexão diária da sua práxis pedagógica, tornando-se um professor consciente de suas ações pedagógicas e cidadãs.

\section{REFERÊNCIAS}

ANDRÉ; Marli; CRUZ, Giseli Barreto da. A produção do conhecimento didático na Rbep (1998-2010, R. bras. Est. pedag., Brasília, v. 93, n. 234, [número especial], maio/ago. 2012.

ARAÚJO, Luiz Carlos Marinho de. A formação docente e a prática de ensino investigativo nas aulas de Ciências Naturais como perspectiva à Alfabetização Científica. Dissertação de Mestrado - Universidade Estadual do Sudoeste da Bahia. Programa de Pós-Graduação Educação Científica e Formação de Professores, Campus, Jequié/BA, 2020.

ASTOLFI, Jean-Pierre; DEVELAY, Michel. A Didática das Ciências. Campinas: Papirus, 1990.

BARDIN, Laurence. Análise de conteúdo. São Paulo: Edições 70, 2016.

BOGDAN, Robert; BIKLEN, Sari. Qualitative research for education. Boston: Allyn and Bacon, Inc., 1982.

CALDEIRA, Anna Maria Salgueiro; ZAIDAN, Samira. Práxis pedagógica: um desafio cotidiano. Paidéia, Belo Horizonte, a. 10, n. 14, p. 15-32 jan./jun. 2013.

CAMPOS, Maria Cristina da Cunha; NIGRO, Rogério Gonçalves. Didática de Ciências: O ensino-aprendizagem como investigação. São Paulo: FTD, 1999.

CANDAU, Vera Maria. A didática em questão. 33 ed. Petrópolis: Vozes, 2012.

CARVAlHo, Anna Maria Pessoa de.; GIL-PÉREZ, Daniel. Formação de professores de Ciências: tendencias e inovações. 10 ed. São Paulo: Cortez, 2011. 
DINIZ-PEREIRA. Júlio Emílio. Da racionalidade técnica à racionalidade crítica: formação docente e transformação social. Perspectivas Em Diálogo Revista de Educação e Sociedade. Perspec. Dial.: Rev. Educ. Soc., Naviraí, v. 1, n. 1, p. 34-42, jan-jun. 2014.

FLICK, Uwe. Desenho da pesquisa qualitativa. Porto Alegre: Artmed, 2009.

FREIRE, Paulo. Pedagogia da autonomia. São Paulo: Paz e Terra, 1996.

GERALDO, Antonio Carlos Hidalgo. Didática de Ciências Naturais: na perspectiva histórica-crítica. 2 ed. Campinas: Autores Associados, 2014.

GIL, Antonio Carlos. Como elaborar projeto de pesquisa. 4 ed. São Paulo: Atlas, 2002.

GOMES, Alberto Albuquerque. A profissão docente em construção: expectativas e conflitos do "ser professor". Perspec. Dial.: Rev. Educ. e Soc., Naviraí, v. 3, n. 5, p. 161-180, jan.-jun. 2016.

IZA, Dijnane Fernanda Vedovatto; et al. Identidade docente: As várias faces da constituição do ser professor. Revista Eletrônica de Educação, v. 8, n. 2, p. 273-292, 2014.

LIBÂNEO, José Carlos. Didática. São Paulo: Cortez, 2006.

LÜDKE, Menga; ANDRÉ, Marli Eliza Dalmazo Afonso. Pesquisa em educação: Abordagem Qualitativa. 2 ed. Rio de Janeiro: E.P.U, 2020.

MARCONI, Maria de Andrade; LAKATOS, Eva Maria. Técnicas de pesquisa. 3. ed. São Paulo: Atlas, 1999.

MARTINS, Pura Lúcia Oliveira. Didática. 1 ed, Curitiba. Intersaberes, 2012.

MELLADO, Vicente; CARRACEDO, Dario Garcia. Contribuciones de la filosofia de la ciencia a la didáctica de las ciencias. Enseñanza de las ciencias, v. 3, 1993.

MINAYO, Maria Cecília de Souza (org.). Avaliação por triangulação de métodos: abordagem de programas sociais. Rio de Janeiro: Fiocruz, 2005.

MIZUKAMI, Maria da Graça Nicoletti. Ensino: As abordagens do processo. São Paulo: EPU, 1986.

MORAES, Roque; GALIAZZI, Maria do Carmo. Análise Textual Discursiva. Ijuí: Unijuí, 2007. 
O'BRIEN, Dan. Introdução à teoria do conhecimento. Lisboa: Gradiva, 2013.

OLIVEIRA, Zilma de Moraes Ramos de; SILVA, Ana Paula Soares; CARDOSO, Fernanda Moreno; AUGUSTO, Silvana De Oliveira. Construção da identidade docente: relatos de educadores de Educação Infantil. Cadernos de Pesquisa, v. 36 , n. 129 , p. 547-571, set./dez. 2006.

PEREIRA; Adriana Soares; FRANCISCATTO, Roberto; SHITSUKA Ricardo; BERTOLDO, Sandra Regina Franciscatto. Didática Geral. 1 ed. Santa Maria: UFSM, 2019.

PIMENTA, Selma Garrido (org.). Saberes pedagógicos e atividade docente. São Paulo: Cortez, 1999.

SANTOS, Ricardo Costa dos; SOUZA, Josefa Eliana. São Cristóvão, Sergipe, Brasil, v. 11, n. 1, Edição Especial, dezembro, 2018.

SUANNO, Marilza; RAJADELL, Núria (org.). Didática e formação de professores: perspectivas e inovações. Goiânia: CEPED, 2012.

TARDIF, Maurice. Saberes docentes e formação profissional. 17. ed., Petrópolis/RJ: Vozes, 2014.

TRIVIÑOS, Augusto Nibaldo Silva. Introdução à pesquisa em ciências sociais: a pesquisa qualitativa em educação. São Paulo: Atlas, 1987. 